\section{ТP Periodica Polytechnica} Chemical Engineering

60(3), pp. 157-164, 2016

DOI: $10.3311 /$ PPch. 8441

Creative Commons Attribution (i)

\title{
The Effect of Thermophoresis on Flame Propagation in Nano-Aluminum and Water Mixtures
}

\author{
Mehdi Bidabadi ${ }^{1}$, Milad Ramezanpour ${ }^{1}$, Moein Mohammadi ${ }^{1 *}$, \\ Jalil Fereidooni ${ }^{1}$
}

RESEARCH ARTICLE

\begin{abstract}
This study investigates the important role of thermophoresis in flame propagation speed of nano-sized aluminum particles and water mixtures. To this aim, a one-dimensional steady state model was developed based on mass and energy conservation equations considering the effect of thermophoresis. In order to simulate the flame propagation speed of nano-sized aluminum particles and liquid water mixtures, the flame structure (the computational domain) was divided into three zones: liquid water zone, preheat zone and reaction zone. The governing conservation equations were solved numerically using a finite-difference method. The predicted results were in reasonable agreement with literature data for the flame propagation speed. The modeling results demonstrated that although the effect of thermophoresis is negligible at micro-scales, it cannot be ignored for nano-sized particles. Furthermore, as the particle size decreases and the equivalence ratio and initial mixture temperature increases; the effect of thermophoresis on the flame propagation speed becomes more significant.
\end{abstract}

\section{Keywords}

Flame propagation speed, Thermophoresis, Nano-aluminum, Water

\footnotetext{
${ }^{1}$ Combustion Research Laboratory, School of Mechanical Engineering, Iran University of Science and Technology (IUST),

Narmak, 16846-13114 Tehran, Iran

*Corresponding author, e-mail: moeinmohammadi@mecheng.iust.ac.ir
}

\section{Introduction}

Reaction between aluminum and water takes place in many explosive and propulsion systems. Aluminum and water have been suggested as propellants for space propulsion [1] and underwater propulsion applications [2]. A lot of attention has been drawn to aluminum-water propellant systems for space exploration and they have been investigated by scientists and researchers for a number of years. In addition to high energyrelease rate of aluminum-water mixtures, the propellant combination and their combustion products are non-toxic and environmentally friendly [1]. Hence, they have been proposed as a replacement for hydrazine in satellites and spacecrafts [3]. Furthermore, the low cost and simplicity of aluminum-water propellants make them suitable as in-situ propellants for lunar and Mars missions [4].

Nano-sized particles show different physical, chemical, electrical, optical and combustion properties compared to larger particles of the same material. The surface-to-volume ratio of nano-sized particles may increase to such an extent that could change the bulk properties of materials, for example, nanosized aluminum particles can increase the propellant burningrate as much as 5-10 times compared to regular aluminum particles. In addition, using nano-sized aluminum particles results in short burning times and low ignition temperatures [5]. As the particle size approaches the nano-scale, most of its properties become size-dependant. Some theoretical models have been developed to study the effect of aluminum particle size on ignition temperature $[6,7]$. However, the proposed models were not consistent with experimental results. Diwan et al. [8] investigated the effect of metal particle size on the velocity of combustion wave propagation in magnesium-water mixtures experimentally and analytically. Temperature profile of the combustion wave and dependence of the front velocity on the magnesium particle diameter were determined.

Experimental studies have been conducted to characterize the combustion of aluminum particles at nano- and micro-scales with water [9-13]. Also, several numerical and analytical models have been developed to get a better understanding of this process [1416]. Sippel et al. [9] studied combustion efficiency of nano-sized 
aluminum particles and ice mixtures. The particle size was $80 \mathrm{~nm}$ and the experiments were performed with equivalence ratios of 1, 0.75 and 0.67 . The results demonstrated that the lower the equivalence ratio, the higher the combustion efficiency. Shmelev and Finyakov [10] investigated the combustion of micronsized aluminum particles and water under various experimental conditions. The pressure component in the burning rate law was determined in nitrogen and argon atmospheres. Risha et al. [17, 18] performed experiments to examine the effect of pressure, mixture composition and particle size on mass burning rates of quasi-homogeneous mixtures of nano-aluminum (38 130nm) and water. It was observed that the burning rate increased as the particle size decreased. Sung \& Shin [19] developed a theoretical model to study premixed combustion characteristics of nano-aluminum and water mixtures. The authors calculated the temperature and flame speed distribution taking into account the effects of particle size as well as initial pressure and temperature. Sundaram et al. $[15,16]$ established a numerical model to predict the flame propagation speed and energy-release profile of nano-sized aluminum and liquid water mixtures. A direct relationship between the particle size and flame thickness was found. In contrast, the flame thickness decreased with increased pressure.

As mentioned before, different models have been developed to study the combustion of aluminum particles with water. However, the effect of thermophoresis on combustion of nanoand micron-sized particles has not been taken into account in previous models. The aim of the present study is to evaluate the importance of this effect on combustion behavior of nano-sized aluminum particles and liquid water mixtures. To this aim, the flame structure was divided into three zones: liquid water zone, preheat zone and reaction zone. The governing conservation equations were solved numerically and some parameters were modeled as black box. For example the chemical kinetics of dust combustion determine the burning time of particle which is a function of oxygen concentration, environmental temperature, particle diameter and etc. The flame propagation speed was calculated and the modeling results were validated using experimental data of Risha et al. [17, 18].

\section{Thermal Model}

\subsection{Thermophoresis}

The particle motion induced by thermal gradients is called thermophoresis. The presence of temperature gradient in the particulate system imposes thermophoretic force on the particles, which leads to faster dispersion of particles in hotter regions than colder regions. As a result of this differential dispersion, the particles migrate toward the colder regions of the flow domain, and consequently they will be accumulated in the colder regions of the particulate system [20].

In general, the effect of thermophoresis on the motion of spherical particles is expressed in terms of the steady-state thermophoretic velocity, which can be calculated as follows [21]:

$$
\boldsymbol{V}_{T}=-K_{t p} \frac{\mu}{\rho} \frac{\nabla T}{T_{u}}
$$

Where $\mu$ is the dynamic viscosity coefficient of the mixture, $\rho$ is the density of the mixture, $\nabla T$ is the temperature gradient, $T_{u}$ is the unburned mixture temperature, and $K_{t p}$ is the coefficient function of the thermophoretic velocity. The function $K_{t p}$ depends on the properties of the fluid and the solid particles and Knudsen number, $K n$, which is defined as the ratio of the mean free path of the molecules, $\lambda$, to the nanoparticle diameter, $d_{p}[20]$ :

$$
K n=\frac{\lambda^{\prime}}{d_{p}},
$$

Several expressions for function $K_{t p}$ have been proposed. The following expression that has been recommended by Talbot et al. [22] is used in this study.

$$
\begin{aligned}
K_{t p} & =\frac{2 C_{s}}{1+3 C_{m} K n} \frac{\left(\frac{\lambda}{\lambda_{p}}+C_{t} K n\right) C_{c}}{1+2 \frac{\lambda}{\lambda_{p}}+2 C_{t} K n} \\
& =\frac{2 C_{s}}{1+3 C_{m} K n} \frac{\left(\lambda+C_{t} \lambda_{p} K n\right) C_{c}}{2 \lambda+\lambda_{p}+2 C_{t} \lambda_{p} K n},
\end{aligned}
$$

In which $\lambda$ is the mixture thermal conductivity, $\lambda_{p}$ is the thermal conductivity coefficient of the particle, $C_{s}, C_{m}$ and $C_{t}$ are constant coefficient and their recommended values are $1.17,1.14$ and 2.18 respectively, and $C_{c}$ is the slip correction factor and is calculated by Eq. (4):

$$
C_{c}=1+K n\left(A_{1}+A_{2} \exp \left(-\frac{2 A_{3}}{K n}\right)\right),
$$

Where the following parameters $A_{1}=1.257, A_{2}=0.40$ and $A_{3}=0.55$ are often used [23].

The nanoparticle mass flux due to thermophoretic effects is described by Eq. (5):

$$
j_{s, T}=\rho Y_{s} V_{T}=-\rho D_{T} \frac{\nabla T}{T_{u}},
$$

Where $D_{T}$ is the thermal diffusion coefficient and is defined as:

$$
D_{T} \equiv K_{t p} \frac{\mu}{\rho} Y_{s},
$$

In which $Y_{S}$ is the nanoparticle mass fraction.

\subsection{Conservation equations}

The mass conservation equation for the nanoparticles takes the following form [24]:

$$
\rho\left(\frac{\partial Y_{s}}{\partial t}+V \cdot \nabla Y_{s}\right)=-\nabla \cdot j_{s, T}-\dot{\omega}
$$


Where $Y_{S}$ represents the nanoparticle mass fraction and $V$ is the mixture velocity. Considering that the particle thermal relaxation time is much smaller than the flow residence time in the flame zone, $\dot{\omega}$ represents the reaction rate as follows [16]:

$$
\dot{\omega}=\frac{\rho Y_{s}}{\tau_{b}}
$$

In which for $\tau_{b}$ as the burning time of nanoparticles that burn under kinetically controlled conditions, $d^{0.3}$ law has been applied, which is defined by the following equation [15]:

$$
\tau_{b}=\frac{d^{0.3}}{C_{2} e^{\frac{E_{b}}{R T}} \cdot X_{e f f} \cdot P^{0.48}}
$$

In which $C_{2}=8.72105, E_{b}=73.6 \mathrm{~kJ} / \mathrm{mol}, d$ is the particle diameter in $\mu m, R$ is the universal gas constant and $X_{\text {eff }}$ is the effective oxidizer mole fraction which includes the concentration of $\mathrm{O}_{2}, \mathrm{CO}_{2}$ and $\mathrm{H}_{2} \mathrm{O}$ as follows:

$$
X_{e f f}=C_{O 2}+0.6 C_{H 2 O}+0.22 C_{C O 2},
$$

Substitution of Eq. (5) into Eq. (7) results in:

$$
\rho\left[\frac{\partial Y_{s}}{\partial t}+V \cdot \nabla Y_{s}\right]=\nabla \cdot\left(\rho D_{T} \frac{\nabla T}{T_{u}}\right)-\dot{\omega},
$$

The energy conservation equation for the mixture is described by Eq. (12) [24]:

$$
\rho c\left[\frac{\partial T}{\partial t}+V \cdot \nabla T\right]=-\nabla \cdot q+h_{p} \nabla \cdot j_{s, T}+\dot{\omega} Q
$$

Where $c$ is the mixture specific heat, $T$ is the mixture temperature, $q$ represents the heat flux vector and is calculated by Eq. (13) [24], $h_{p}=c_{p, s} T$ is the nanoparticle specific enthalpy, $c_{p, s}$ is the nanoparticle specific heat and $Q$ is the heat release per unit mass of the fuel.

$$
q=-\lambda \nabla T+h_{p} j_{s, T}
$$

Considering that $\nabla \cdot h_{p} j_{s, T}=h_{p} \nabla \cdot j_{s, T}+j_{s, T} \cdot \nabla h_{p}$ and $\nabla h_{p}=c_{p, s} \nabla T$, substitution of Eq. (13) into Eq. (12) results in:

$$
\rho c_{p}\left[\frac{\partial T}{\partial t}+V \cdot \nabla T\right]=\nabla \cdot \lambda \nabla T-c_{p, s} j_{s, T} \cdot \nabla T+\dot{\omega}
$$

Substituting Eq. (5) into Eq. (12), the energy conservation equation can be written as:

$$
\rho c_{p}\left[\frac{\partial T}{\partial t}+V \cdot \nabla T\right]=\nabla \cdot \lambda \nabla T+\rho c_{p, s}\left(D_{T} \frac{\nabla T \cdot \nabla T}{T_{u}}\right)+\dot{\omega} Q,
$$

Eq. (11) and (15) form the governing equations of the system that can be solved simultaneously for $Y_{s}$ and $T$ to find the nanoparticle mass fraction and temperature distribution in the fluid domain.

\subsection{Model assumptions and solution procedure}

In this study, the model has been developed assuming that:

1) Particles are spherical and have the same size.

2) The coordinate system is attached to the propagating flame.

3) The flame is planar.

4) The pressure is constant.

5) Gravitational effects and heat transfer by radiation are neglected.

To model the flame propagation in a chemically reacting system consisting of nano-sized aluminum particles and liquid water, the governing conservation equations are solved for a one dimensional steady state problem. Therefore, Eq. (11) and (15) are simplified to:

$$
\rho u \frac{d Y_{s}}{d x}=\frac{d}{d x}\left(\frac{\rho D_{T}}{T_{u}} \frac{d T}{d x}\right)-\frac{\rho Y_{s}}{\tau_{b}},
$$

$$
\rho u c_{p} \frac{d T}{d x}=\frac{d}{d x}\left(\lambda \frac{d T}{d x}\right)+\frac{\rho D_{T} c_{p, s}}{T_{u}}\left(\frac{d T}{d x}\right)^{2}+\frac{\rho Q Y_{s}}{\tau_{b}},
$$

To obtain the flame propagation speed, the flame structure is divided into three zones: liquid water zone, preheat zone, and reaction zone. The following assumptions are considered in each zone:

Liquid water zone $\left(-\infty<x<-\ell, T_{\infty}<T<T_{v}\right)$ :

Where $T_{\infty}$ is the initial temperature of the mixture and $T_{v}$ is the water boiling temperature, and in this zone, reaction between metal and liquid water does not occur.

Preheat zone $\left(-\ell<x<0, T_{v}<T<T_{i g}\right)$ :

Where $\ell$ is the preheat zone thickness and $T_{i g}$ is the ignition temperature of the nano-aluminum particles. No reaction occurred in this region.

Reaction zone $\left(0<x<+\infty, T_{i g}<T<T_{a d}\right)$ :

Where $T_{a d}$ is adiabatic flame temperature. The combustion reaction between nano-sized aluminum particles and water occurs only in this zone.

Figure 1 shows the flame structure of nano-aluminum and water mixture as mentioned above.

\subsubsection{Boundary conditions}

The boundary and interfacial conditions applied to solve Eq. (16) and (17) are as follows:

$$
\begin{gathered}
x \rightarrow-\infty: \quad Y_{s}=Y_{s, u}, \quad T=T_{\infty} \\
x=-\ell:\left.\quad Y_{s}\right|_{-l^{-}}=\left.Y_{s}\right|_{-l^{+}}
\end{gathered}
$$




$$
\begin{gathered}
x=-\ell: \quad T=T_{v}, \\
\left.\lambda_{I} \frac{d T}{d x}\right|_{-l^{-}}+(1-\Phi) \rho_{H_{2} O(l)} S_{L} Q_{v}=\left.\lambda_{I I} \frac{d T}{d x}\right|_{-l^{+}} \\
x=0:\left.\quad Y_{s}\right|_{0^{-}}=\left.Y_{s}\right|_{0^{+}} \\
x=0: \quad T=T_{i g},\left.\quad \lambda_{I I} \frac{d T}{d x}\right|_{0^{-}}=\left.\lambda_{I I I} \frac{d T}{d x}\right|_{0^{+}} \\
x=+\infty: \quad Y_{s}=0, \quad \frac{d T}{d x}=0
\end{gathered}
$$

Where $Y_{S, u}$ represents the unburned particle mass fraction, $\Phi$ represents the particle volume fraction, $\rho_{H 2 O}$ is the density of the liquid water, $\lambda_{I}, \lambda_{I I}, \lambda_{I I I}$ are thermal conductivity coefficients of the nanoparticle in liquid water zone, preheat zone and reaction zone respectively, $S_{L}$ is the laminar flame speed and $Q_{v}$ is the heat of water vaporization.
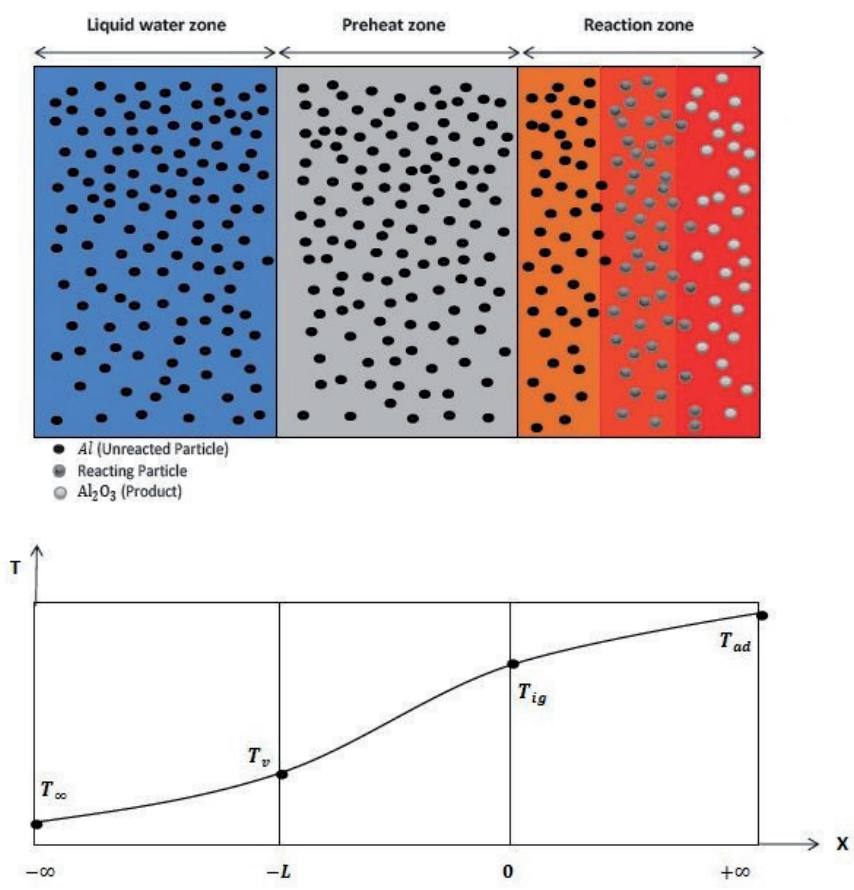

Fig. 1 Schematic of the multi-zone flame structure for the flame front propagation of the nano-sized aluminum particle and water mixture

\subsubsection{Nondimensionalization}

To investigate the effect of different parameters on the flame propagation speed and better analyze the system, the following dimensionless parameters are introduced:

$$
\chi=\int_{0}^{x} \frac{\rho_{u} S_{L} c_{p}}{\lambda} d x \Rightarrow \frac{d}{d x}=\frac{\rho_{u} S_{L} c_{p}}{\lambda} \frac{d}{d \chi}
$$

$$
\left\{\begin{array}{l}
\Upsilon=\frac{Y_{s}}{Y_{s, u}}, \theta=\frac{T-T_{\infty}}{T_{i g}-T_{\infty}}, \\
\gamma=\frac{c_{p, s} Y_{s, u}}{c_{p}}, N_{T T}=\frac{\lambda T_{\infty} Y_{s, u}}{\rho D_{T} c_{p}\left(T_{i g}-T_{\infty}\right)}, \\
\zeta=\frac{\rho \lambda}{\left(\rho_{u} S_{L}\right)^{2} c_{p} \tau_{b}}, \eta=\frac{Q Y_{s, u}}{c_{p}\left(T_{i g}-T_{\infty}\right)},
\end{array}\right.
$$

In which $\rho_{u}$ is the density of the unburned nanoparticle. Substitution of the normalized variables defined in Eq. (24) and (25) into Eq. (16) and (17) results in the dimensionless mass and energy conservation equations as follows:

$$
\begin{gathered}
\frac{d \gamma}{d \chi}=\frac{1}{N_{T T}} \frac{d^{2} \theta}{d \chi^{2}}-\zeta \Upsilon \\
\frac{d \theta}{d \chi}=\frac{d^{2} \theta}{d \chi^{2}}+\frac{\gamma}{N_{T T}}\left(\frac{d \theta}{d \chi}\right)^{2}+\zeta \eta \Upsilon
\end{gathered}
$$

The dimensionless governing equations along with the dimensionless boundary and interfacial conditions for each zone are summarized as follows:

\section{Liquid water zone:}

$$
\begin{gathered}
\frac{d \gamma}{d \chi}=\frac{1}{N_{T T}} \frac{d^{2} \theta}{d \chi^{2}} \\
\Upsilon_{\chi \rightarrow-\infty}=1 \\
\frac{d \theta}{d \chi}=\frac{d^{2} \theta}{d \chi^{2}}+\frac{\gamma}{N_{T T}}\left(\frac{d \theta}{d \chi}\right)^{2} \\
\theta_{\chi \rightarrow-\infty}=0, \quad \theta_{\chi=-\delta_{v}}=\theta_{v}
\end{gathered}
$$

Where $\delta_{v}$ is described by Eq. (32):

$$
\delta_{v}=\int_{0}^{\ell} \frac{\rho_{u} S_{L} c_{p}}{\lambda} d x
$$

\section{Preheat zone:}

$$
\begin{gathered}
\frac{d \Upsilon}{d \chi}=\frac{1}{N_{T T}} \frac{d^{2} \theta}{d \chi^{2}} \\
\Upsilon_{\chi=-\delta_{v}^{-}}=\Upsilon_{\chi=-\delta_{v}^{+}} \\
\frac{d \theta}{d \chi}=\frac{d^{2} \theta}{d \chi^{2}}+\frac{\gamma}{N_{T T}}\left(\frac{d \theta}{d \chi}\right)^{2}
\end{gathered}
$$




$$
\theta_{\chi=-\delta_{v}}=\theta_{v}, \quad \theta_{\chi=0}=1
$$

\section{Reaction zone:}

$$
\begin{gathered}
\frac{d \Upsilon}{d \chi}=\frac{1}{N_{T T}} \frac{d^{2} \theta}{d \chi^{2}}-\zeta \\
\Upsilon_{\chi=0^{-}}=\Upsilon_{\chi=0^{+}}, \Upsilon_{\chi \rightarrow+\infty}=0 \\
\frac{d \theta}{d \chi}=\frac{d^{2} \theta}{d \chi^{2}}+\frac{\gamma}{N_{T T}}\left(\frac{d \theta}{d \chi}\right)^{2}+\zeta \eta \Upsilon \\
\theta_{\chi=0}=1, \frac{d \theta}{d \chi}{ }_{(\chi \rightarrow+\infty)}=0
\end{gathered}
$$

The preheat zone thickness, $l$ and the flame speed, $S_{L}$ can be obtained applying the following dimensionless equations:

$$
\begin{aligned}
& \frac{d \theta}{d \chi_{\chi=-\delta_{v}^{-}}}+\frac{(1-\Phi) \rho_{H_{2} O(l)} Q_{v}}{\rho_{u} c_{p}\left(T_{i g}-T_{u}\right)}=\frac{d \theta}{d \chi_{\chi=-\delta_{v}^{*}}} \\
& \frac{d \theta}{d \chi_{\chi=0^{-}}}=\frac{d \theta}{d \chi_{\chi=0^{+}}}
\end{aligned}
$$

\subsection{Thermophysical properties of the mixture}

In this section, the expressions applied to calculate thermophyscial properties of the mixture are described. The density of the nanoparticles and base fluid are used to calculate the density of the mixture as below:

$$
\rho=\Phi \rho_{p}+(1-\Phi) \rho_{f}
$$

Where $\Phi$ is the particle volume fraction and $\rho_{p}$ and $\rho_{f}$ represent the density of nanoparticles and base fluid respectively. The mixture specific heat is described by Eq. (44) assuming that the nanoparticles and base fluid are in thermal equilibrium.

$$
c_{p}=\frac{\Phi \rho_{p} c_{p, s}+(1-\Phi) \rho_{f} c_{p, f}}{\rho}
$$

There are a lot of parameters influencing the viscosity of a mixture including nanoparticles [25]. However, an accurate theoretical formula that can predict the mixture viscosity is not currently available. The following expression suggested by De Bruijn [26] is applied in this study.

$$
\mu=\mu_{f}\left(1+2.5 \Phi+4.698 \Phi^{2}\right)
$$

In which $\mu_{f}$ is the dynamic viscosity coefficient of the base fluid.

The thermal conductivity of spherical particles, $\lambda_{e}$ randomly dissipated in a continuous medium has been modelled by Maxwell [27] as below:

$$
\frac{\lambda_{e}}{\lambda_{g}}=\left(1-2 \varphi_{s} \frac{1-\lambda_{s} / \lambda_{g}}{2+\lambda_{s} / \lambda_{g}}\right) /\left(1+\varphi_{s} \frac{1-\lambda_{s} / \lambda_{g}}{2+\lambda_{s} / \lambda_{g}}\right)
$$

Where $\lambda_{s}$ and $\lambda_{g}$ represent the thermal conductivity of the discrete and continuous phases respectively and $\varphi_{S}$ is the volume fraction of the discrete phase. This model can only be applied when the volume fraction of the discrete phase is low.

\section{Results and discussion}

The governing conservation equations of the system were solved numerically using a finite difference method. Using dimensionless parameters, the effect of the particle diameter, the equivalence ratio, and the initial mixture temperature were analyzed as well.

Figure 2 shows the effect of thermophoresis on the laminar flame speed for a stoichiometric mixture at various particle diameters and pressure of $3 \mathrm{MPa}$ in which experimental data were available for validation. The model predicts that the flame speed increases taking into account the effect of thermophoresis. In addition, the thermophoretic effect decreases as the particle size increases and it becomes negligible at micro-scales. Also, the flame propagation speed increases with decreased particle size which can be attributed to the increase in specific area of particles and consequently the decrease in particle burning time. It is also in agreement with literature reports [28].

The experimental data of Risha et al. [17, 18] were used to validate the model. As shown in Fig. 2, both modeling and experimental results show that the laminar flame speed increases as the particle size decreases and the predicted results are in reasonable agreement with the experimental data for the laminar flame speed. From Figure 2 one can conclude that the results obtained from this model taking into account the effect of thermophoresis show better agreement with the experimental data in comparison with the case without considering the thermophoresis.

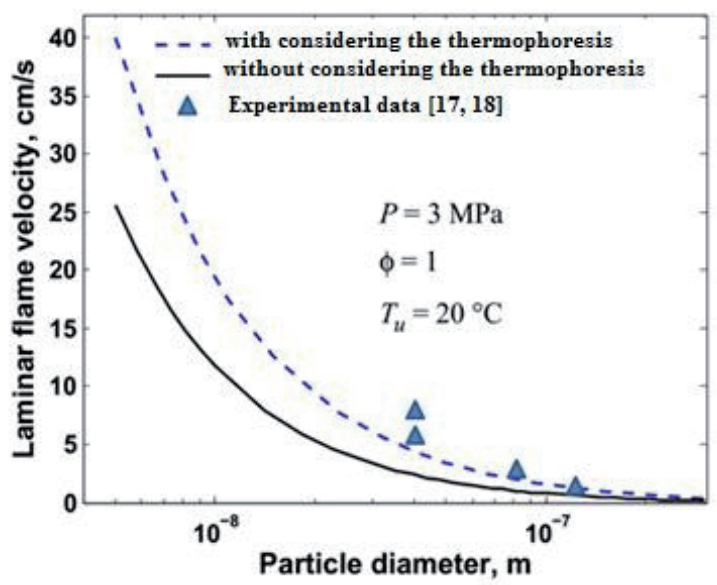

Fig. 2 The effect of thermophoresis on the laminar flame speed of nanoaluminum and water mixtures at different particle diameters 
Figure 3 illustrates the variation of the laminar flame speed with equivalence ratio at a pressure of $3 \mathrm{MPa}$ and initial mixture temperature of $20{ }^{\circ} \mathrm{C}$ for $10 \mathrm{~nm}$ particles. The modeling results reveal that the flame speed increases as the equivalence ratio increases from 0.87 to 1 .

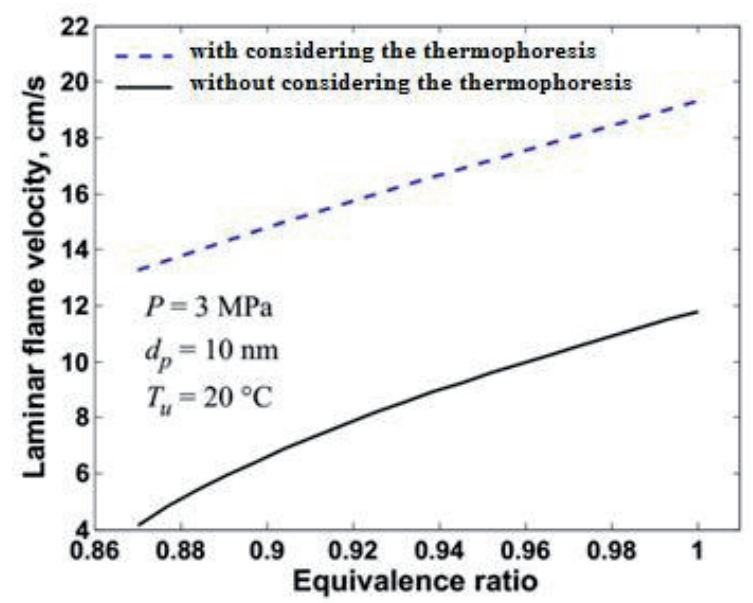

Fig. 3 The effect of thermophoresis on the laminar flame speed of nanoaluminum and water mixtures at different equivalence ratios

The effect of the initial temperature of the mixture on the flame propagation speed is demonstrated in Fig. 4. The model indicates that the initial temperature of the mixture has a direct effect on the flame speed. As it can be seen in this figure, at higher initial temperature of the mixture, the effect of thermophoresis on the flame propagation speed becomes less significant.

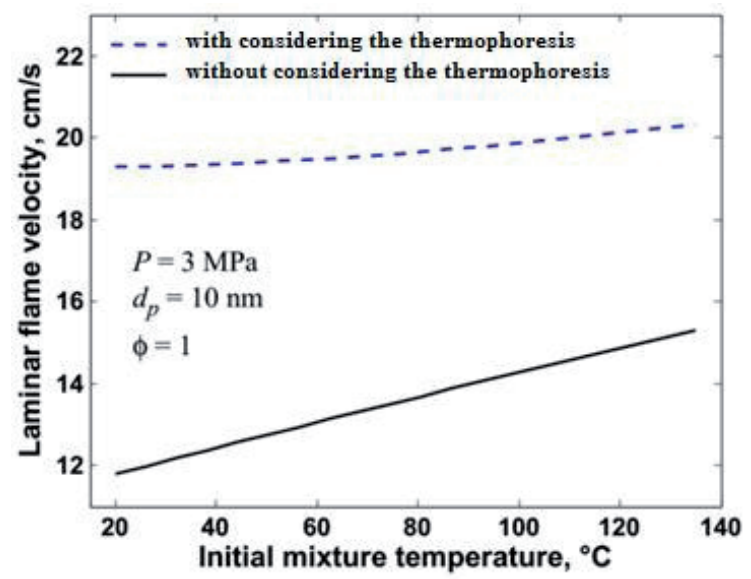

Fig. 4 The effect of thermophoresis on the laminar flame speed of nanoaluminum and water mixtures at different initial mixture temperatures

The effect of thermophoresis on the temperature profile of nano-aluminum and water mixtures at a pressure of $3 \mathrm{MPa}$ and initial mixture temperature of $20^{\circ} \mathrm{C}$ for $10 \mathrm{~nm}$ particles is demonstrated in Fig. 5. As it is clear, although the effects of thermophoresis is negligible in liquid water and preheat zones, it cannot be ignored in reaction zone and temperature increases taking into account the effect of thermophoresis. As it can be seen in this figure, the difference between the values of final temperature for two states, with and without consideration of thermophoresis effect, is about $300 \mathrm{~K}$.

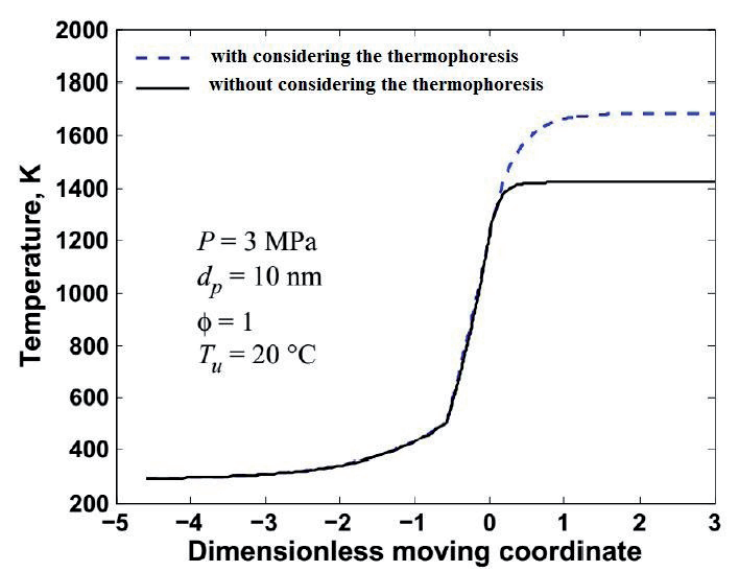

Fig. 5 The effect of thermophoresis on the temperature profile of nanoaluminum and water mixtures

Figure 6 illustrates the temperature profile of nano-aluminum and water mixture with considering the thermophoresis effect at equivalence ratios of 0.9 and 1 (stoichiometric concentration). The particle diameter, initial mixture temperature and pressure are $10 \mathrm{~nm}, 20^{\circ} \mathrm{C}$ and $3 \mathrm{MPa}$, respectively. As it can be seen in this figure, the effect of equivalence ratio in liquid water and preheat zones is negligible, but it cannot be ignored in reaction zone and the final temperature has higher value for the stoichiometric concentration $(\phi=1)$.

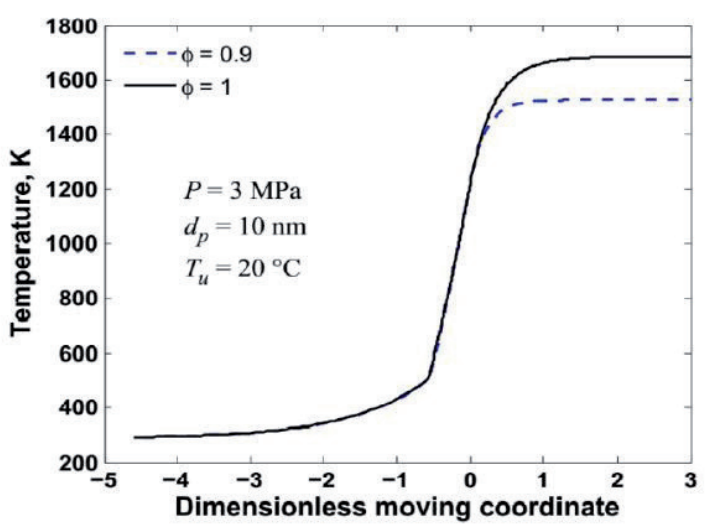

Fig. 6 Temperature profile of nano-aluminum and water mixtures combustion for different values of equivalence ratio $(\varphi)$ with consideration of the thermophoresis effect

\section{Conclusions}

The effect of thermophoresis on the flame propagation speed of the nano-aluminum and water mixtures was studied theoretically. A numerical model was developed based on the mass and energy conservation equations. The laminar flame speed was calculated as a function of the aluminum particle size, the equivalence ratio and the initial mixture temperature. 
According to the modeling results, although the effect of thermophoresis is negligible at micro-scales, it cannot be ignored for nano-sized particles. The model predicts that the laminar flame speed increases with decreased particle size and increased equivalence ratio. Moreover, the laminar flame speed tends to have higher values as the initial mixture temperature increases. It should be also noted that the effect of thermophoresis on the laminar flame speed becomes significant with decreasing the particle size and increasing the equivalence ratio and the initial temperature of the mixture.

The proposed model was validated using the experimental data of Risha et al. [17, 18]. Reasonable agreement between the modeling and experimental results demonstrated that this model is suitable for quantitative estimation of the thermophoretic effect on the flame propagation speed of nano-sized aluminum particles and liquid water mixtures.

\section{Nomenclature}

$\begin{array}{ll}\mathrm{A}_{1}, \mathrm{~A}_{2}, \mathrm{~A}_{3} & \text { Constant coefficients } \\ C_{c} & \text { Slip correction factor } \\ C_{S}, C_{m}, C_{\mathrm{t}} & \text { Constant coefficients } \\ c & \text { Specific heat capacity of mixture }[\mathrm{J} /(\mathrm{kg} \mathrm{K})] \\ c_{p, s} & \text { Nanoparticle specific heat capacity }[\mathrm{J} /(\mathrm{kg} . \mathrm{K})] \\ D_{T} & \text { Thermal diffusion coefficient } \\ d_{p} & \text { Nanoparticle diameter [m] } \\ h_{p} & \text { Nanoparticle specific enthalpy }[\mathrm{J} / \mathrm{kg}] \\ \mathbf{j}_{S, T} & \text { Nanoparticle mass flux }\left[\mathrm{kg} /\left(\mathrm{m}^{2} . \mathrm{s}\right)\right] \\ K_{t p} & \text { Coefficient function of thermophoretic } \\ & \text { velocity } \\ K n & \text { Knudsen number } \\ l & \text { Preheat zone thickness [m] } \\ N_{T T} & \text { Defined dimensionless parameter } \\ Q & \text { Heat release per unit mass of fuel }[\mathrm{J} / \mathrm{kg}] \\ Q_{v} & \text { Heat of water vaporization }[\mathrm{J}] \\ q & \left.\left.\text { Heat flux [J/(m }{ }^{2} . \mathrm{s}\right)\right] \\ S_{L} & \text { Laminar flame speed [m/s] } \\ T & \text { Mixture temperature }[\mathrm{K}] \\ \mathrm{t} & \text { Time [s] } \\ \mathrm{x} & \text { Cartesian space coordinate }[\mathrm{m}] \\ X_{e f f} & \text { Effective oxidizer mole fraction } \\ V & \text { Mixture velocity [m/s] } \\ Y_{S} & \text { Nanoparticle mass fraction } \\ \theta, \gamma & \text { Defined dimensionless parameters } \\ \lambda & \text { Thermal conductivity }[\mathrm{W} /(\mathrm{m} . \mathrm{K})] \\ \lambda_{I}, \lambda_{I I}, \lambda_{I I I} & \text { Thermal conductivity coefficients of } \\ \lambda^{\prime} & \text { Nanoparticle in each zone } \\ \mu & \text { Water molecule mean free path }[\mathrm{m}] \\ \xi & \text { Dynamic viscosity coefficient of } \\ & \text { mixture [Pa.s] } \\ & \text { Defined dimensionless parameter } \\ & \end{array}$
Density of mixture $\left[\mathrm{kg} / \mathrm{m}^{3}\right]$
Nanoparticle burning time [s]
Defined dimensionless parameter
Particle volume fraction
Volume fraction for discrete regime
Defined dimensionless coordinate
Reaction rate $\left[\mathrm{kg} /\left(\mathrm{m}^{3} . \mathrm{s}\right)\right]$

\section{Subscripts}

$\begin{array}{ll}\mathrm{p} & \text { Particle } \\ \mathrm{s} & \text { Discrete regime } \\ \mathrm{u} & \text { Unburned } \\ \mathrm{H}_{2} \mathrm{O} & \text { Liquid water } \\ \mathrm{f} & \text { Base fluid } \\ \mathrm{g} & \text { Continuous regime } \\ \mathrm{ig} & \text { Ignition point } \\ v & \text { Vaporization point } \\ \mathrm{T} & \text { Thermophoretic } \\ \mathrm{ad} & \text { Adiabatic }\end{array}$

\section{References}

[1] Ingenito, A., Bruno, C. "Using aluminum for space propulsion." Journal of Propulsion and Power. 20(6), pp. 1056-1063. 2004. DOI: $10.2514 / 1.5132$

[2] Foote, J. P., Thompson, B. R., Lineberry, J. T. "Combustion of aluminum with steam for underwater propulsion." In: Advances in Chemical Propulsion. (Roy, G. D. (ed.)) pp. 133-146. CRC Press, 2010. DOI: $10.1201 / 9781420040685 . c h 8$

[3] Shafirovich, E., Bocanegra, P. E., Chauveau, C., Gökalp, I. "Nanoaluminum-Water Slurry: A Novel "Green" Propellant for Space Applications." In: Proceedings of the 2nd International Conference on Green Propellants for Space Propulsion. Cagliary, Sardinia, Italy, June 7-8, 2004.

[4] Risha, G. A., et al. "Novel Energetic Materials For Space Propulsion." Department of Mechanical and Nuclear Engineering, Pennsylvania State University. 2011.

[5] Parr, T., Johnson, C., Hanson-Parr, D., Higa, K., Wilson, K. "Evaluation of advanced fuels for underwater propulsion." In: 39th JANNAF Combustion Subcommittee Meeting. Colorado Springs. 2003.

[6] Trunov, M. A., Schoenitz, M., Dreizin, E. L. "Effect of polymorphic phase transformations in alumina layer on ignition of aluminium particles." Combustion Theory and Modelling. 10(4), pp. 603-623. 2006. DOI: 10.1080/13647830600578506

[7] Eisenreich, N., Fietzek, H., del Mar Juez-Lorenzo, M., Kolarik, V., Koleczko, A., Weiser, V. "On the Mechanism of Low Temperature Oxidation for Aluminum Particles down to the Nano-Scale." Propellants, Explosives, Pyrotechnics. 29(3), pp. 137-145. 2004. DOI: $10.1002 /$ prep. 200400045

[8] Diwan, M., Hanna, D., Shafirovich, E., Varma, A. "Combustion wave propagation in magnesium/water mixtures: experiments and model." Chemical Engineering Science. 65(1), pp. 80-87. 2010. DOI: 10.1016/j.ces.2009.01.069

[9] Sippel, T. R., Pourpoint, T. L., Son, S. F. "Combustion of Nano-aluminum and Water Propellants: Effect of Equivalence Ratio and Safety/ Aging Characterization." Propellants, Explosives, Pyrotechnics. 38(1), pp. 56-66. 2013. DOI: 10.1002/prep.201200143 
[10] Shmelev, V. M., Finyakov, S. V. "Specifics of the combustion of aluminum-water mixtures." Russian Journal of Physical Chemistry B. 7(4), pp. 437-447. 2013. DOI:10.1134/S1990793113040106

[11] Risha, G. A., Connell Jr, T. L., Yetter, R. A., Sundaram, D. S., Yang, V. "Combustion of frozen nano-aluminum and water mixtures." Journal of Propulsion and Power. 30(1), pp. 133-142. 2013. DOI: $10.2514 / 1 . B 34783$

[12] Pourpoint, T. L., Wood, T. D., Pfeil, M. A., Tsohas, J., Son, S. F. "Feasibility study and demonstration of an aluminum and ice solid propellant." International Journal of Aerospace Engineering. Article ID 874076. 2012. DOI: $10.1155 / 2012 / 874076$

[13] Wood, T. D., Pfeil, M. A., Pourpoint, T. L., Son, S. F. "Aluminum-ice (ALICE) propellants for hydrogen generation and propulsion." In: 45th AIAA/ASME/SAE/ASE Joint Propulsion Conference \& Exhibit, Denver, Colorado, August 2-5, 2009. DOI: 10.2514/6.2009-4877

[14] Huang, Y., Risha, G. A., Yang, V., Yetter, R. A. "Analysis of nano-aluminum particle dust cloud combustion in different oxidizer environments." In: 43rd AIAA Aerospace Sciences Meeting and Exhibit, Reno, Nevada, USA, January 10-13, 2005. DOI: 10.2514/6.2005-738

[15] Sundaram, D. S., Puri, P., Huang, Y., Yetter, R. A., Yang, V., Risha, G. A. "Flame Propagation of Nanoaluminum-Water Mixtures." In: 447th AIAA Aerospace Sciences Meeting including The New Horizons Forum and Aerospace Exposition. Orlando, Florida, January 5-8, 2009. DOI: $10.2514 / 6.2009-641$

[16] Sundaram, D. S., Yang, V., Huang, Y., Risha, G. A., Yetter, R. A. "Effects of particle size and pressure on combustion of nano-aluminum particles and liquid water." Combustion and Flame. 160(10), pp. 2251-2259. 2013. DOI:10.1016/j.combustflame.2013.04.025

[17] Risha, G. A., Son, S. F., Yetter, R. A., Yang, V., Tappan, B. C. "Combustion of nano-aluminum and liquid water." Proceedings of the Combustion Institute. 31(2), pp. 2029-2036. 2007. DOI: 10.1016/j.proci.2006.08.056

[18] Risha, G. A., Sabourin, J. L., Yang, V., Yetter, R. A., Son, S. F.,Tappan, B. C. "Combustion and conversion efficiency of nanoaluminum-water mixtures." Combustion Science and Technology. 180(12), pp. 2127-2142. 2008. DOI: $10.1080 / 00102200802414873$
[19] Sung, H. G., Shin, J. S. "Theoretical Study on Premixed Flames of Nano Aluminum Particles and Water Mixture." Applied Mechanics and Materials. 284-287, pp. 567-571. 2013.

DOI: 10.4028/www.scientific.net/AMM.284-287.567

[20] Michaelides, E. E. "Transport properties of nanofluids. A critical review." Journal of Non-Equilibrium Thermodynamics. 38(1), pp. 1-79. 2013. DOI: $10.1515 /$ jnetdy-2012-0023

[21] Michaelides, E. E. "Particles, bubbles \& drops: their motion, heat and mass transfer." World Scientific, 2006.

[22] Talbot, L., Cheng, R. K., Schefer, R. W., Willis, D. R. "Thermophoresis of particles in a heated boundary layer." Journal of Fluid Mechanics. 101(04), pp. 737-758. 1980. DOI: 10.1017/S0022112080001905

[23] Davies, C. N. "Definitive equations for the fluid resistance of spheres." Proceedings of the Physical Society. 57(4), pp. 259-270. 1945. DOI: 10.1088/0959-5309/57/4/301

[24] Bird, R. B., Warren E. S., Edwin N. L. "Transport phenomena." John Wiley \& Sons, 2007.

[25] Kumar, P. C. M., Kumar, J., Suresh, S. "Review on Nanofluid Theoretical Viscosity Models."' International Journal of Engineering Innovations and Research. 1(2), pp. 182-188. 2012.

[26] De Bruijn, H. "The viscosity of suspensions of spherical particles. (The fundamental $\eta$-c and $\varphi$ relations)." Recueil des Travaux Chimiques des Pays-Bas. 61(12), pp. 863-874. 1942. DOI: 10.1002/recl.19420611205

[27] Maxwell, J. C. "Electricity and Magnetism, Clarendon Press." Oxford, 1873.

[28] Bidabadi, M., Fereidooni, J., Hosseini, S. N., Asadollahzadeh, P. "Investigation of particle size effect on flame velocity in the combustion of nano/micron-sized aluminum particles in air." In: Proceedings of the Institution of Mechanical Engineers, Part G: Journal of Aerospace Engineering. 228(2), pp. 297-304. 2014. DOI: 10.1177/0954410012471767 